\title{
Opening up the culture black box in community technology design
}

\author{
Amalia Sabiescu ${ }^{1} \cdot{\text { Aldo de } \text { Moor }^{2} \cdot \text { Nemanja Memarovic }}^{3}$
}

Published online: 30 July 2019

(c) Springer-Verlag London Ltd., part of Springer Nature 2019

\section{Community technology design}

Community technology design is informed by and studied in various and overlapping fields of research and practice, including human-computer interaction (HCI), design studies, computer science, community studies, and community informatics. In all of these fields there has been of recent a growing concern for cultural aspects and how they influence the design and usage of technology. This has fuelled the development of new frameworks, approaches, and exemplar empirical studies that have tackled the integration of cultural aspects to inform the design of technology in community settings.

Yet, the question of culture and its infusion into community technology design is so broad, and the contributions to date framed by such a variety of disciplines, that we are very far from reaching integration of frameworks and perspectives. The important question of how we account for cultural issues in the design of community technology may receive very different answers from design and technology studies compared to community or cultural studies. The richness in this variety of perspectives also inevitably leads to fragmentation. Given the acceptance and use of such very different, disciplinary-bound perspectives and approaches, the interpretation and communication of similar problems and solutions often become difficult across fields of study.

Intentionally broad in (inter)disciplinary scope, this special issue approaches cultural issues in community

Amalia Sabiescu

a.g.sabiescu@lboro.ac.uk

Aldo de Moor

ademoor@communitysense.nl

Nemanja Memarovic

nemanja.memarovic@gmail.com

1 Institute for Media and Creative Industries, Loughborough University London, London, UK

2 CommunitySense, Tilburg, The Netherlands

3 Imnoo AG, Glattbrugg, Switzerland technology design having a wide-ranging disciplinary embedding as a strength rather than a limitation. The point of departure for this special issue-a workshop we have organised at the 2015 edition of the Communities \& Technologies Conference held in Limerick, Ireland-aimed

"to bring together academics and practitioners from different domains such as computer science, urban design, interactive art, cultural anthropology and social sciences who share a common interest in exploring the challenges and opportunities in the design space of ICTs, culture and communities" (He et al., 2015).

The workshop received multidisciplinary contributions that inspired very engaged workshop discussions, which we structured in three themes:

Theme 1: Cultural requirements for technology design

Theme 2: Cultural translation and design processes

Theme 3: Culturally aware tools and systems

Continuing from the workshop, both a public call for papers and an invited call directed to scholars with a significant track record in community technology design were issued. The calls for papers asked for:

1. "Submissions that engage broadly with the role of culture within technology design and usage for, with and by communities, as well as

2. proposals for approaches, tools, conceptual and methodological frameworks, case studies and best practices in community-based design that exploit cultural diversity as asset and seek to encourage intercultural interactions."

Eight interdisciplinary papers have been selected for the special issue, which examine the role of culture in potentially informing, supporting, and driving the design, appropriation and use of technology in community settings. Some of them focus on the actual design process, and some others look at technology in use and the implications of design decisions already made and how they affect, afford and constrain use or are creatively interpreted in often unforeseen ways. The 
papers selected hereby provide responses to the following central questions:

How can we identify, analyse and interpret cultural aspects to inform the design of community technology?

To what extent and how do cultural aspects affect technology appropriation and use?

What are the implications of these understandings for future technology design?

\section{The articles}

The articles in this special issue offer theoretical, methodological, and empirical contributions, each building on an empirical body of evidence described through case studies. Ammar Halabi and Basile Zimmermann open the series of articles with a contribution that proposes an original framework for tracing and analysing cultural phenomena in the design and use of technology. The paper, titled "Waves and Forms: Constructing the cultural in design" introduces the waves and forms framework as mid-way between two perspectives on theorising culture and technology in HCI: the first is based on generalisation and the creation of taxonomies and cultural dimensions to inform design, represented in the work of Hofstede (1991), Marcus and Gould (2000) and E.T. Hall (1976). The second approaches culture in terms of subjective meaning-making and interaction which are context-specific, fluid and dynamic, represented by Irani et al.'s (2010) work on postcolonial computing and that of Merritt and Stolterman (2012) on cultural hybridity in participatory design. In what the authors call the taxonomic perspective, categories are pre-defined before the design process, while in the contingent perspective, any cultural factors for informing design are constructed within the study. Halabi and Zimmermann argue that it is possible to bridge the taxonomic and the contingent perspectives, so that the concerns of both approaches are attended to: employing taxonomies and categories for bringing structure to design processes, while also attending to the fluid, contingent, dynamic and shifting nature of culture.

The waves and forms framework (Zimmermann 2015) adopts an interpretive lens that concentrates on the materiality of culture-its material expressions and the way they circulate from one context to another, whether these are inscribed in physical media (written poem), performance (oral performance of poem), or interaction (audience listening to poem). These material manifestations are interpreted in terms of shapes, the material traces of any process or phenomenon. These are essentialised in the primordial components of waves, "the smallest level of shape that matter can take"; and forms, "an aggregate of waves that is identified by a human being", and therefore subjective interpretations of waves. In this view, culture is then the dynamic circulation of waves, constantly identified and interpreted by human beings as forms. Culture is thus both material and subjective. The framework meets the concerns of the taxonomic perspective and its preoccupation with structure, by conceptualising material cultural manifestations to develop categories; at the same time, it responds to principles of the contingent perspective, by allowing these categories to be developed within the study, focusing on material manifestations in the research context.

Halabi and Zimmermann argue that the waves and forms framework is a suitable vehicle for identifying cultural aspects with a bearing on design, insofar as it enables the identification and classification of forms with multiple instances, and how these change dynamically and are interpreted subjectively in different settings. They introduce the case study of a voluntary student community in Syria, and apply the framework to answer the question:

"What happens when a design element of the internet infrastructure - an aggregate of waves-circulates through communication infrastructure, computing devices and people, and gets appropriated by local voluntary communities in Syria?"

In answer to this question, the waves and forms framework enables the identification of key dynamics characterising the relation between technology and local practices. The analysis evidences how local political constraints regarding freedom of association in Syria on the one hand, and affordances and constraints inscribed in the design of web-based and social media on the other hand, framed and determined the nuances of interaction, cooperation, and conflict in the voluntary community studied, as well as its use of media platforms.

The paper by Heike Winschiers-Theophilus, Tariq Zaman, and Colin Stanley focuses on the relationship between designers and communities from different cultural backgrounds as a central defining element of the design process. The paper, titled "A Classification of cultural engagements in community technology design: Introducing a transcultural approach", proposes a paradigm shift to a transcultural mode of engagement in community technology design. Transcultural design moves beyond individual cultures and epistemologies to mark the creation of a new design space in which all parties contribute, but which transcends unilateral viewpoints.

The authors make a strong case for the importance of acknowledging the cultural stance adopted in a community technology design endeavour, which comes to affect the entire design process. The article reviews previous modes of cultural engagement in community technology design, namely cross-, inter-, and multicultural design, mirroring the three waves in HCI research (as conceptualised by Bødker 2006): the first one framed by cognitive science, in which 
users are seen as subjects; the second one focusing on collaboration and interaction; and the third wave on meaningmaking and embodied experience. In the authors' interpretation, each mode of cultural engagement comes with an array of tools and methodologies: cross-cultural engagement is associated with user-centred design privileging the employment of user and cultural models; intercultural engagement privileges participatory design, and design initiatives that are engaging and empowering for communities; and multicultural engagement leans on interaction design, favouring the making of experience and reciprocity between design teams and communities. The transcultural approach endorses community-based co-design methods, aiming for achieving unity between different epistemologies.

Winschiers-Theophilus, Zaman and Stanley argue that the mode of cultural engagement adopted influences fundamentally the process of design, the relationships established between design teams and communities and the relevance and meaning of design outcomes. This is exemplified by the kind of narratives created in each type of endeavour. Cross-cultural design, with its focus on cultural difference, produces narratives of 'the other'; despite the participatory process in intercultural design, the narratives produced are counter-narratives, in which communities engage with the stories previously circulated about them by dominant factions in society (Sabiescu 2015). Narratives become harmonious in multicultural modes of engagement, but only the transcultural mode of engagement enables the creation of narratives that result from adequate processes of reflection and embody participants' evolved understandings of issues tackled and design aims.

Entering a transcultural mode of engagement can only happen, however, in the frame of a trustful and long-term collaboration between design and research teams and communities. Time is one of the most important factors to consider to reach readiness to engage in transcultural design by both designers and communities. The authors demonstrate the value of lengthy, enduring collaborations, through a detailed description of their work with indigenous communities in Namibia and Malaysia. The case studies introduced and the temporal descriptions of collaborations show how inevitably at the beginning it is difficult to avoid a crosscultural mode of engagement. Its focus on difference is evident in both the relationships established and in the artefacts produced. As design teams and communities continue to work together, and as roles shift and bend in participatory initiatives, slowly the transcultural design space advocated by the authors starts to be shaped and instantiated, from which new types of artefacts emerge, some not previously possible before these levels of collaboration, blending of epistemologies and creativity are reached.

The article by Lara Piccolo and Roberto Pereira, titled "Culture-based artefacts to inform ICT design:
Foundations and practice", offers an approach for infusing cultural aspects in the design of information and communication technology (ICT), based on the use of culture-based conceptual artefacts. The authors' point of departure is that cultural issues should be considered not as an add-on but as integral part of the theoretical and methodological frameworks that guide design. This process can be facilitated by the employment of conceptual tools that support the identification of cultural issues and their use to develop design requirements. This is exemplified by a series of culture-based artefacts employed by the authors in the two cases reported in the paper: the Organisational Onion, the Value Pie (Pereira and Baranauskas 2014), Hall's Primary Message Systems (Hall 1959) and Mapping Social Norms (Stamper 1993; Stamper et al. 2000). These have been interpreted within the socially aware design approach espoused by the authors and framed by an organisational semiotics theoretical stance, which offers socially and culturally informed methods for the design of information systems. The paper showcases the application of the conceptual artefacts in two case studies in Brazil, the first aiming to raise awareness of domestic energy consumption and the second for developing a national networking platform for inclusive education teachers. Piccolo and Pereira conclude that a sociotechnical approach relying on the use of conceptual tools is essential for gauging cultural issues in community technology design, and is not dependent on the design methods used. The tools they describe can be equally useful in participatory design processes involving stakeholders directly, as well as in studies informed by ethnography and mixed methods. The key benefit these bring is an enhanced capacity to see beyond the technical and uncover aspects related to local cultures and norms that would otherwise remain invisible.

In their article, "Poetry as a cross-cultural analysis and sensitizing tool in design”, Patrizia Marti and Ward van der Houwen propose a new method for cross-cultural design, which leverages the evocative qualities of poetry as a cultural and art form. The method uses poems as a way to identify cultural values and inspire new, culturally informed ways to design. The process is highly experiential and reflexive, and is articulated across six phases: experience, confrontation, acquaintance, extraction, integration and reflection. Marti and van der Houwen's approach marks a step forth in state of the art research on poetry and design: from a concern with the aesthetics of interaction to cultural characteristics of interaction. Poetry is used as an analytical and experiential tool for cultural elements, and as a tool to embody these elements in design. Another way their paper marks advancement from the state of the art is in harnessing some of the most elusive features of poetry as a design tool: its ability to evoke feelings, emotions and understandings difficult to put into words and to support mindful experiencing. 
"Poetry is about thoughtfulness and observation. It is a way to sensitize our design skills on a experiential level of emotion and being: rich and profoundly human. It enables the mind to pick up on subtleties, cultural and interpersonal, that analytical design tools are insensitive to."

This is done by conceiving the design process as an iteration of moments dedicated to abstract analysis followed by concrete experience. For instance, to afford experiencing a poem without resorting to conceptualisation, the authors advise listening to the poem in the original language and pay attention to the voice, tone, rhythm and other non-conceptual elements of the poem.

Leena Ventä-Olkkonen, Netta Iivari and Arto Lanamäki offer a structured analysis and interpretation of the role of cultural values in shaping the design, development and usage of information systems. Their article, titled "In sweet harmony or in bitter discord? How cultural values and stakeholder requirements shape and users read an urban computing technology" reports on the case of 18 public displays designed and deployed in the city of Oulu, Finland. The authors describe a study for shedding light on the factors that influenced display usage, and the reasons behind the low levels of interaction with most displays. The study employs a theoretical framework drawing on symbolic interpretations of culture in anthropology, based on the work of Clifford Geertz (1973). The focus on meaning-making pertaining to the symbolic school of anthropology is extended to the interpretations of values and cultural values as fluid and emergent, prone to be continuously negotiated and interpreted subjectively. To analyse matches and mismatches between design and use, the authors draw on cultural studies scholar Stuart Hall's (1980) encoding and decoding interpretive lens in communication processes. This is employed to interpret design as a process of encoding and use as a process of decoding meaning. In both processes, the cultural values of design stakeholders and users have a prevalent part to play.

Ventä-Olkkonen, Iivari and Lanamäki's paper contributes, firstly, a detailed analysis of the matches and mismatches in the design and reading of information systems, analysed by means of corresponding and conflicting values adopted by designers, other design stakeholders and users. The paper hints at the limits that come with focusing the analysis of design bias on the designers alone. By including in their study other stakeholders that influence design, such as advertisers for the public displays and municipality representatives, they show that the influence of human choice on the design is plural, diverse and often contradictory. The cultural value lens allows them to identify diversity and plurality there where we may at first sight only see homogenous entities. This makes into a second contribution of the paper, an original understanding of cultural diversity characterising seemingly cohesive entities such as design and multi-stakeholder project teams.

Caitlin Bentley, David Nemer and Sara Vannini's paper focuses on processes of community engagement with technology, and how these can become more aware and reflective using visual methodologies framed by a cultural identity lens. Their paper, titled “'When words become unclear': Unmasking ICT through visual methodologies in participatory ICT4D", is framed by an ICT for development (ICT4D) disciplinary lens, concerned with differences and inequalities in technology use in the Global South. They argue that participatory methodologies in ICT4D practice often rely on instrumental and functional interpretations of technology, which may explain why ICT actually come to strengthen rather than bridge inequalities. Instead, critical engagement with technology is needed to enable communities to drive social change. Part of the role of participatory ICT4D projects is to equip participants with these capacities. Bentley, Nemer and Vannini define critical engagement with ICT through a cultural identity lens, drawing on Stuart Hall's theorisation of cultural identity (1996) and its interpretation by Hakken and Mate (2014). The authors single-out for their analysis three factors to be met for critical ICT engagement: situational awareness of ICTs, reflexive ICT practice, and power over ICT use. Through three case studies, they show how visual methodologies can be used to identify cultural issues around technology use and derive implications for technology design.

The article by Bentley and her colleagues invites reflection on the importance of developing a critical consciousness of interacting with ICT, especially in contexts marred by social inequality such as communities in the Global South. Their first contribution here is to conceptualise critical ICT engagement with a focus on cultural issues, and to propose three factors that can be used as analytical categories in research focusing on these issues. Second, the article showcases through three detailed case studies the role of visual methodologies employed in a manner sensitive to cultural factors, for supporting more aware and critical engagement with ICT. In all contexts researched, participants had seldom or never before reflected on their ICT practice. The visual interventions encouraged and enabled them to think about and reflect on their technology interactions. While single interventions such as the ones reported in the case studies are not sufficient on their own for developing enduring reflective engagement with ICTs, the article draws attention to a vital component that is missing and could be considered in future ICT projects with communities in the Global South.

The contribution by Mauro Sarrica, Tom Denison, Larry Stillman, Tapas Chakraborty and Priordarshine Auvi is positioned as well in the field of ICT4D and community informatics. The paper, titled "'What do others think?' An emic approach to Participatory Action Research in Bangladesh”, 
reports on a participatory research project on information technology and women empowerment and the role of participatory action research (PAR) as a tool for bridging cultural differences. Their study adopts a holistic, emic approach to culture, and uses it to frame the participatory process and the encounters between the research and design team and the communities involved, as intercultural exchanges. The use of participatory approaches is deemed to enhance a project's likelihood of achieving effective, sustainable outcomes. Furthermore, when framed by an emic approach to culture, the aim is to ensure "that material and immaterial artefacts developed in projects not only meet community needs, but are based on recognition of culturally embedded meanings and practices at both micro- and macro-levels of a project". Thus, the paper reports on the various clashes and differences encountered, bridged or persisting throughout the project between different cultures - of the local communities, researchers' and organisational cultures associated with the local NGOs and the development stakeholders involved. The paper concludes that "listening to the voices of the participants, supporting them in the development of locally valid practices, and accepting the mutual transformation of the meanings attached to project is the only way to build a longterm sustainable project, able to foster community empowerment through ICTs."

Ahmed Al-Rawi's paper, "Facebook and virtual nationhood: Social media and the Arab Canadians community", examines the role of social media in shaping the identity of online communities. The study focuses on a Facebook group dedicated to Arab Canadians and uses two theoretical lenses to shed light on how the social media service provides a platform for 'virtual nationhood': First, Benedict Anderson's concept of 'imagined communities' is used to examine the reality of a community constructed by members' projected, imagined ideas of belonging. Second, the paper looks at the horizontal and vertical flows of communication and the role of online moderation through the theory of network gatekeeping by Barzilai-Nahon (2008).

Al-Rawi's paper is significant for inviting further reflection on how we think of and conceptualise communities and identities. The author shows that even when a community is formed by members with loose, subjective and varied ideas of their host country and how they are connected to it, it can still instil positive feelings that affect the way their diaspora accommodates and integrates within. To this end, the study focuses on members' feelings expressed through social media engagement and analysed through sentiment analysis. On this basis, the article sheds light on the role of media in shaping and building identities. It highlights one element in the design of the Facebook platform-online moderationand shows how this fundamentally influences the processes of communication and exchange. This is important, AlRawi argues, as the type of communication flows on social media, and how gatekeeping occurs, further affect the type of engagement possible for its users and ways of conceiving one's identity link with the community.

\section{Opening the culture black box: communities, culture, and technology design}

The eight papers in this special issue come with various theoretical and methodological approaches for teasing out the cultural in community technology design. Specifically, they focus on different types of communities, adopt different ways to look at and analyse culture and use different strategies for engaging with cultural aspects in the design process. Their contributions are significant insofar as they cover a wide spectrum of perspectives and approaches, not restricted to dominant narratives. For instance, the communities covered are local communities as well as communities of interest and of practice; theoretical frameworks for examining cultural aspects range from the ones based on cultural dimensions and generalised features, to context-specific, contingent ones. And approaches for infusing cultural aspects in the design process range from specific methodologies such as interpretations of participatory design, to the use of conceptual artefacts or artistic interventions to enrich the design process. In the following sections of this editorial piece, we map the various contributions put forth by the papers along three axes captured by the questions:

1. What do we mean by community?

2. What is culture and how do we analyse it?

3. How can/does/should culture inform/influence design and its outcomes?

\section{Making sense of communities}

The papers cover a wide range of community types through the case studies introduced. Some involve local communities, such as the OvaHerero and OvaHimba indigenous communities in Namibia, and the Penan indigenous community in the Long Lamai village in Malaysia in the case studies by Winschiers-Theophilus, Zaman and Stanley. Al-Rawi's paper covers online communities, and the case study in the paper by Ventä-Olkkonen, Iivari and Lanamäki focuses on the community made of citizens in a Finnish city. Case studies also cover different types of communities in the same paper. For instance, Bentley, Nemer and Vannini apply their analysis of visual methodologies to three very different communities: favelas in Brazil, members of a multinational NGO in Southern Africa, and users of multimedia centres in Mozambique. Piccolo and Pereira's case studies exemplify 
a local community in an urban area and the community of practice made of inclusive education teachers in Brazil.

The articles also put forth different ways of conceptualising and analysing communities. Winschiers-Theophilus, Zaman and Stanley show that what we tend to call 'local communities' are far from being homogenous, and instead may display multiple factions, viewpoints (often at odds) and unequal power relationships that eventually show as well in the design process. Similarly, Ventä-Olkkonen, Iivari and Lanamäki evidence plurality and diversity within communities, as well as evolution of tastes, preferences and values. Al-Rawi uses Benedict Anderson's concept of imagined communities to examine communities with loose relationships and scarce or even no interactions where the communal sense is only an imagined, subjective construct adopted by members. Despite this, imagined communities can provide members with real feelings of togetherness, unity and even empowerment. And Piccolo and Pereira apply an organisational semiotics perspective that sees communities and organisations as systems of social norms, drawing on Stamper et al. (2000). This focus on norms links communities to their culture: the norms accepted by community members guide members' behaviour, and eventually come to affect the way they perceive and engage with the world.

\section{Seeing culture}

Winschiers-Theophilus, Zaman and Stanley bring an original perspective to the argument 'why culture matters'. The authors argue that the cultural stance adopted-whether consciously or unconsciously-in design with communities, comes to influence the levels of awareness invested in that endeavour, and where that awareness is directed: at the methods, the tools, the process, the collaboration, the entities involved, and so on. Thus, different paradigms such as cross-, inter- and multicultural design will each come with a different focus: in cross-cultural design the focus is on difference, whether it is about acknowledging or bridging it; in intercultural design on engagement and empowerment; in multicultural design on reciprocity. And in the new transcultural approach advocated by the authors, on collaboration. Different foci and levels of awareness influence the quality and mode of design, and how cultural aspects make their way into the design process.

Most evident across the multiple ways of conceptualising culture in the papers is the association with two major perspectives for tackling the relation between culture and technology in design and HCI. These are defined by Halabi and Zimmermann as the taxonomic and the contingent perspectives, and we will use this terminology in this editorial piece. As briefly outlined above, the taxonomic perspective looks at culture in terms of categories and dimensions that can be defined before a study and then applied in different contexts. Its purpose is to bring clarity, structure and focus to the design process by offering analytical categories to work with. While still broadly popular, this perspective has encountered major criticism. As Marsden (2008) argues, the use of averages in design is of limited significance, as these fail to capture the subjective experience of individual users. To counter these limits, the contingent school focuses instead on the subjective meaning-making, fluid, interactional qualities of culture. This perspective has its limits as well, one being that the fluid and elusive nature of culture can be found daunting to identify, analyse and translate into concrete design requirements, as well as to make comparisons across cases.

A good number of papers in the special issue associate their approach with one of the schools, whether implicitly or explicitly. For instance, Marti and van der Houwen frame their approach to poetry-inspired design in a cultural stance that elicits the dynamic, interactional, and subjective qualities of culture, focusing on those that are most elusive and difficult to put into words, but which poetry can evoke experientially. Ventä-Olkkonen, Iivari and Lanamäki interpret culture with a focus on the process of meaning-making, drawing on the symbolic school in anthropology represented by Clifford Geertz. This focus on meaning further extends to the analysis of cultural values embraced by the various stakeholders engaged in the design and use of information systems, analysing values as subjective, shifting and evolving, even in the course of a single project. This resonates as well with the emic approach to culture espoused by Sarrica et al., with its focus on situated understandings coming from within the community.

On the other hand, Piccolo and Pereira embrace a perspective on culture drawing on E. T. Hall, by which culture encompasses the ways of thinking and organisation of individual, family and community life, which Hall formalizes in its 10 Primary Message Systems and three levels of communication and interaction: formal, informal and technical. Moreover, the authors employ as well a kindred theoretical stance that sees culture in terms of sociocultural norms that guide the behaviour of people, structured as well in formal, informal and technical levels, drawing on Stamper et al. (2000). Piccolo and Pereira's approach can be associated with the taxonomic perspective and their study shows that this can still be interpreted and employed in ways that are resonant with local cultural specificity.

There are also interpretations of culture beyond the anthropological use of the term. Ventä-Olkkonen, Iivari and Lanamäki interpret culture as:

"the shared (although evolving) culture that emerged within the project, which likely has been shaped by various kinds of organizational, occupational, profes- 
sional, and community of practice cultures to which the project members belong and have experience of."

One implication of this lens is how we make sense of cultural diversity. Whereas cultural diversity is often thought of in terms of racial, ethnic, language diversity, their work shows that diversity can instead be encountered also within seemingly homogenous units, such as the various stakeholders engaged in a city-commissioned technology project.

"However, values are not viewed as a static, fixed, shared set that can be comprehensively captured, but instead as a plural and emergent constellation that is continuously open to interpretation and negotiation. Such negotiation takes place within stakeholder groups, as well as between them."

Halabi and Zimmermann's study focuses on the cultural characteristics immediately surrounding processes of technology design and adoption. In their analysis, they identify and analyse the cultural aspects inscribed in technology designed for a global user base (such as Facebook) and oppose it to the local context and practices in which it gets appropriated. Thus, culture as conceptualised in their study:

"is less related to the distinction between, say, "western" and "Syrian", as much as it relates to the tension between the "global design and governance of the Internet and applications running on it" and "the functioning of a local voluntary community in Damascus". This tension is our design point of departure."

\section{From translation to design}

\subsection{Theorising culture and design}

Approaches to design and means of informing design through cultural aspects are intricately related to the perspectives adopted for conceptualising and analysing culture. The theoretical approaches outlined above provide broad lenses and subtly direct attention and methodological choices. The contingent perspective to cultural issues, for instance, does not ask for specific methodologies, yet it provides a point of convergence by emphasising an analytical focus on meaningmaking and interaction. Thus, the contingent lens provides fertile ground for original methodologies and methodological interpretations. An original approach to design is proposed in this special issue by Marti and van der Houwen, using poetry as a tool capable of instilling cultural values and sensitivity towards cultural aspects in the design process. Their method compels designer's experiential engagement with culture, through iterative cycles of abstract analysis and subjective experience. This is thought to equip design with qualities not afforded by more rational and analytical design processes, as exemplified in the reflections of the Industrial Design students who applied the method:

"The team reported that the main lessons learned was how to master a value-driven process. They felt like they were designing on a deeper level, more from feelings and intuiting than from a problem-solving perspective."

"The Chinese student derived cultural differences from simply listening to, and reciting poems. She had the impression that "Dutch poems are cold, Gronings poems are far, Indonesian poems have a sense of tolerance but not giving up hope at the same time, Chinese poems are simple and clear, English poems are direct, and Spanish poems are always in a hurry"... Even though she couldn't understand most of foreign poems, she showed to be able to absorb information and feelings of different cultures and embody them in the final design."

Within the taxonomic perspective, Piccolo and Pereira adopt an approach framed by socially-aware computing, which emphasises the influence of sociocultural aspects on technology design and use. They advocate the use of conceptual artefacts based on cultural dimensions to examine the design context and ease the identification and treatment of cultural issues. These artefacts do not depend on any specific design methodology, and can be coupled with both participatory design and other non-participatory design approaches as exemplified by the two case studies reported in their paper.

Another mapping of approaches to cultural issues in design is covered in the paper by Winschiers-Theophilus, Zaman and Stanley, namely three different takes on cultural engagement- cross-, inter- and multicultural designreflecting the three waves in HCI. Some of the papers in this special issue explicitly associate their approach with cross-cultural design, such as for instance the paper by Marti and van der Houwen.

Some of the papers put forth their own, original theoretical perspective. Halabi and Zimmermann propose an approach to analysing cultural factors in design that sits in between the taxonomic and contingent perspectives, based on identifying and examining the material traces of culture. In the case study they describe, the waves and forms framework developed by one of the authors enabled the identification of cultural influences in the use of technology by a Syrian voluntary community.

After reviewing the cross-, inter- and multicultural approaches, Winschiers-Theophilus, Zaman and Stanley describe a transcultural design paradigm. Leaping from a focus on difference in cross-cultural design, engagement in intercultural design, and reciprocity in multicultural design, it is only in a transcultural mode of engagement that we can go 
beyond culture and beyond methods, and instead direct our awareness towards aspects that make the specific designercommunity collaboration fruitful. The transcultural mode of engagement resides in a blending of epistemologies, new creative modes, ways of conceptualising and solutions that emerge from a novel design space, with equal roles, shares and contributions. The implications of embracing transcultural design are hinted at through the case studies, showing that the outcomes of transcultural design are not necessarily harmonious and strictly relevant for the community as a whole, as attempted in multicultural design. Rather, they can spark debates, as shown by the authors in the case of the Oroo' language application developed for the Penan Long Lamai indigenous tribe in Malaysia. Working in a transcultural mode of engagement, a mixed team of designers and community members decided that language preservation should consider its evolution and incorporation of new words, rather than limit itself to the documentation of vocabulary frozen at a moment in time. This way the language could become or continue to be relevant for Penan youth, with very different interests and lifestyles compared to older generations. This solution was not taken easily by other indigenous tribes and researchers, who thought this approach does nothing more than 'pollute' the original language. Thus, the authors argue that in transcultural design a novel design space is created, where issues are re-framed from different perspectives and wherefrom new solutions can emerge. In the Malaysian case described, this involved a re-conceptualisation of what language preservation is or should be, from documenting and storing vocabulary, to enabling vocabulary evolution to stay relevant for young generations.

\subsection{Deepening our understanding}

A cross-reading of the papers reveals as well two themes enriching the culture-design connections that are tackled in several papers to different effect. A first theme regards the relationship between designers and communities as a significant aspect of the design process. The question is central to those instances of community-based design that take place in contexts different from the dominant use base, including diasporic and deprived communities in Western societies, and those in the Global South. The adoption, appropriation and use of technologies, or the design of novel technologies in these settings deserves special attention, due to the cultural differences between designers and communities. Three papers in this special issue examine these aspects through case studies in the Global South.

The paper by Winschiers-Theophilus and colleagues uses empirical evidence from research with indigenous communities in Namibia and Malaysia. The two case studies report on long-term design engagements between communities and researcher-designers. It is this long-term engagement that enabled the authors to examine at length evolving relationships between designers and communities, and map them along with shifting approaches to culture and design. It is also in the frame of these long-term engagements that it is even possible to enter a transcultural mode of engagement.

Reporting on cases from Africa and Latin America, Bentley, Nemer and Vannini similarly point to the importance of acknowledging cultural differences between researchers and community members. They argue that employing visual methodologies through a cultural identity lens can contribute to raising participants' critical consciousness in engaging with ICTs. This process also involves a great deal of reflexivity on the side of the researchers. The three case studies, written in first person, demonstrate the process of reflection by researchers and its bearing on the understandings resulting from research.

The paper by Sarrica et al. illustrates the merits but also the limits of participatory action research in bridging the various cultures instantiated in the ICT4D project they report on: the culture of the local Bangladeshi communities involved, the culture of the research team, and the organisational cultures associated with the national and international partnerships that made the project possible. The project revealed quite a number of discrepancies and incompatibilities between these cultures. For instance, the researchers' concern with documentation is in stark contrast with the local NGOs activity line, which did not rely on ethnographic ways of recording and reporting. Thus, one of the challenges of the project was in "bringing a technology faculty into alignment with a major player in international development and its practical, rather than research interests, as well as local Bangladeshi culture and ways of doing." While the paper only reports on a pilot intervention, it suggests that harmonious bridging of cultural differences takes time and a self-reflective attitude on the side of participants, similarly to Bentley, Nemer and Vannini's conclusion.

The implications from these three papers are that acknowledging cultural issues is significant beyond design and the concrete design outcomes. Furthermore, ICT4D and community design initiatives can play a significant role in driving change in communities in the Global South. Thus, it is important to adopt methodologies that integrate attention to local cultural aspects and change and which involve the designers reflecting on their own thinking and participation. While unbiased, clinically distant facilitation may indeed be impossible to achieve (Sabiescu et al. 2014), reflective engagement can ensure the basis for dialogic relationships where the biases and influences of each party are treated transparently.

A second additional theme is that of dealing with divergence and conflict in relation to design. Ventä-Olkkonen, Iivari and Lanamäki use a cultural value lens for analysing issues of compatibility and conflict in design. Their paper offers a detailed, attentive analysis of matches and 
mismatches between the values of designers, other design stakeholders and users. This analysis provides a plausible explanation behind the lack of interaction with public displays, attributing it to a cultural value mismatch. This compels us to extend the definition of culture and cultural difference, and acknowledge how difference occurs even where we see apparent homogeneity.

"Specifically interesting from the perspective of technology design is the compatibility or fit of these values. (..) This article shows both compatible and conflicting values that pulled the project in different directions. The trajectory of the project can be characterized as reacting to these contesting influences that shifted the project in an abundance of twists and turns."

Halabi and Zimmermann focus on a different aspect related to conflict and design. Their analysis closes in on an element of web-based information portals-the fact that web portals and domain accounts can be controlled by a single user, even when portals are collectively managed. This affordance means that factions or even just one member of the community can take control of all operations, possibly jeopardizing the "legitimacy of design" (Whitworth and De Moor 2003). Having acknowledged the far-reaching implications of this design element in the case study they report on, the authors used these insights in the design of a new collaborative platform with collective ownership and management patterns inscribed in the technical affordances. A similar observation is made in Al-Rawi's analysis of how a social media design element influences online interaction and in the long run affects patterns of user engagement. While social media platforms such as Facebook offer the affordances for online communities to form and gather, its design elements also constrain and limit interactions and engagement patterns.

\section{Concluding remarks}

A common pattern across the special issue contributions is that all papers advocate the social embedding of technology and the importance of looking beyond mere technical and functional analysis for community technology to become and stay relevant for its stakeholders. Another running thread is advocating for cultural analysis in situ, even in instances where taxonomic perspectives are used. In essence, most authors agree that the analysis of culture is a situated process, it starts in the field. Even more so, what makes the cultural is at least in part dictated by the context and not pre-defined. Some of the papers support the use of pre-defined analytical categories and cultural dimensions, as they may, for instance, suggest new angles of analysis and help to compare lessons learnt across cases. However, they endorse as well the view that new insights may come from the field, and some of these may be unexpected, even incompatible, but still valid. This stance may lead to extending the definition of what we actually mean by culture, as reported by Halabi and Zimmermann:

"We have thus purposely avoided defining "Syrian culture", and decided to focus on general processes of transformation and becoming. The reason for doing so is that we take the cultural to be established locally, in the frame of the study and the interests of the actors involved, and only through close contact with physical data."

Indeed, Halabi and Zimmermann, as reflected in the title of their paper, advocate "constructing the cultural in design", not with predefined categories to fill, but through close observation of situated realities and patterns in field data. This stance puts them in a position to ask a bold question:

"One might as well ask here if the category of culture is needed at all in design. Indeed, it seems possible, maybe even desirable, to achieve culturally-sensitive design without resorting to the label "culture", as long as the design effort is based on categories grounded in patterns observed in the field and its actors."

Other papers in the special issue adopt as well open, fluid understandings of the term culture: from the most traditional, anthropological sense of the term, to the cultures of design teams that affect design choices, to pieces of software and details of Internet infrastructure being considered 'cultural' as well, by tracing back the process of their making. More so, in this same vein, Winschiers-Theophilus and her colleagues propose a design approach that goes beyond methods and beyond culture. A transcultural design approach is forged in long-term engagements with communities, and draws equally on the epistemologies, viewpoints and ideas of the parties involved across design teams and communities.

While attempting to bypass the cultural category all together appears like a bold step, we should acknowledge that the authors that propose it do so while recognising the need for close, attentive and detailed analysis of and engagement with community life, views and values, no matter how we come to define these. Thus, the 'beyond culture' stance is one in which attention to cultural issues has been masterfully assimilated, so that it becomes integral part of the design process.

A final theme coming out of this special issue regards the role of intentionality in culturally informed design. In particular, the analysis of Ventä-Olkkonen, Iivari and Lanamäki suggests that designers and other stakeholders' cultural values will profoundly affect design, even (or especially) when these values are not explicitly acknowledged as a design influence. In other words, in some form or another culture will always have a key influence on 
design. The questions are: Whose culture? And is this process transparent and intentional? Thus, adopting a culturally informed approach to design is in the first place about making certain the design process examines cultural aspects to make them visible, and to decide transparently whether those aspects should influence the design outcomes. For instance, self-reflection by designers can contribute to lowering designer unconscious bias.

Furthermore, as Halabi et al. (2015) argue, the process of aligning design intentions in community-based design is one of the most complex and difficult to grasp, as the transition from exploratory, research-intensive phases to formulating design goals is elusive and poorly conceptualised, even more so in multi-stakeholder and participatory projects. According to them, collective intentionality that adequately grasps community aims and wants is built in time through enduring collaboration and can be analysed in terms of knowledge invested and acquired by stakeholders, their engagement, and the conceptual and methodological frames brought to the table. Perhaps one practical way forward to fostering such collective intentionality could be the responsible development and use of sociotechnical pattern languages, such as the Liberating Voices Pattern Language for Communication Revolution (Schuler 2008). These culturally-infused pattern languages for developing and especially contextualizing, applying and using communication technologies to empower communities are not prescriptive, but intend to make creative good practice suggestions for responsible community systems design. As they are based on many different examples and points of view, they literally help to liberate voices in coming up with sociotechnical systems that work for them and do justice to their unique community needs and values.

In conclusion, we have thoroughly enjoyed our journey through this mostly uncharted territory where culture and technology are still often at such opposite poles. The articles collected in this issue are excellent examples of how a wealth of cultural analysis approaches could be a key step forward towards enabling the crystallisation of collective intentions in technology design that adequately reflect of necessity widely divergent community views and aims.

Acknowledgements We would like to thank Karamjit S. Gill for suggesting the timeliness of a special issue to take the pulse of this interdisciplinary area of research and practice. We also thank the authors for contributing inspiring and informative papers, and the reviewers for their fast turnaround and thoughtful comments on the contributions.

\section{References}

Barzilai-Nahon K (2008) Toward a theory of network gatekeeping: a framework for exploring information control. J Am Soc Inform Sci Technol 59:1493-1512

Bødker S (2006) When second wave HCI meets third wave challenges. In Proceedings of the 4th Nordic conference on Human-computer interaction: changing roles. ACM, pp. 1-8
Geertz C (1973) The interpretation of cultures: selected essays. Basic Books, New York

Hakken D, Maté P (2014) The culture question in participatory design. ACM, New York, pp 87-91

Halabi A, Sabiescu A, David S, Vannini S, Nemer D (2015) From exploration to design: aligning intentionality in community informatics projects. J Community Inform 11(3). Retrieved from http://www. ci-journal.net/index.php/ciej/article/view/1160

Hall ET (1959) The silent language. Anchor Books, New York

Hall ET (1976) Beyond culture. Anchor Doubleday Press, Garden City

Hall S (1980) Encoding/decoding. In: Hall S, Hobson D, Lowe A, Willis $\mathrm{P}$ (eds) Culture, media, language: working papers in cultural studies, 1972-79. Hutchinson, London, pp 128-138

Hall S (1996) Introduction. In: Hall S, du Gay P (eds) Questions of cultural identity. SAGE, London, pp 1-17

He HA, Memarovic N, Sabiescu A, de Moor A (2015) CulTech2015: Cultural diversity and technology design. In: Proceedings of the 7th International Conference on Communities and Technologies. ACM, pp. 153-156

Hofstede G (1991) Cultures and organisations: software of the mind. McGraw-Hill, New York

Irani L, Vertesi J, Dourish P, Philip K, Grinter RE. 2010. Postcolonial Computing: a Lens on Design and Development. In: Proceedings of the 28th International Conference on Human Factors in Computing Systems-CHI'10. ACM Press, New York, NY, p 1311

Marcus A, Gould EW (2000) Crosscurrents: cultural dimensions and global web user-interface design. Interactions 7(4):32-46

Marsden G, Maunder A, Parker M (2008) People are people, but technology is not technology. Philos Trans R Soc 366(2008):3795-3804

Merritt S, Stolterman E (2012) Cultural Hybridity in Participatory Design. In: Proceedings of the 12th Participatory Design Conference-PDC'12. ACM Press, New York, NY, p 73

Pereira R, Baranauskas MCC (2014) Value pie: a culturally informed conceptual scheme for understanding values in design. In: Kurosu M (ed) Human-computer interaction. Theories, methods, and tools. Springer, Cham, pp 122-133

Sabiescu A (2015) Mainstream narratives and counter-narratives in the representation of the other: the case of the Romani ethnic minority. In: Bidwell NJ, Winschiers-Theophilus H (eds) At the intersection of indigenous and traditional knowledge and technology design. Informing Science Press, Santa Rosa

Sabiescu AG, David S van Zyl I, Cantoni L (2014) Emerging spaces in community-based participatory design: reflections from two case studies. In: Proceedings of the 13th Participatory Design Conference: Research Papers-Volume 1. ACM. pp 1-10

Schuler D (2008) Liberating voices: a pattern language for communication revolution. The MIT Press, Cambridge

Stamper RK (1993) Social norms in requirements analysis—an outline of MEASUR. requirements engineering technical and social aspects. Academic Press, New York

Stamper R, Liu K, Hafkamp M, Ades Y (2000) Understanding the roles of signs and norms in organizations-a semiotic approach to information systems design. Behav Inf Technol 19(1):15-27

Whitworth B, de Moor A (2003) Legitimate by design: towards trusted socio-technical systems. Behav Inf Technol 22(1):31-51

Zimmermann B (2015) Waves and forms: electronic music devices and computer encodings in China. MIT Press, Cambridge

Publisher's Note Springer Nature remains neutral with regard to jurisdictional claims in published maps and institutional affiliations. 